\title{
Altered GABA and somatostatin modulation of proprioceptive feedback after spinal cord injury in lamprey
}

Erik Svensson*, Oliver Kim, David Parker

Department of Physiology, Development, and Neuroscience, University of Cambridge, Downing site, Cambridge CB2 3DY, UK.

\footnotetext{
* Corresponding Author: Erik Svensson. E-mail: erik.svensson@epfl.ch. Present address:

Laboratory of Neuronal Microcircuitry, Brain Mind Institute, École Polytechnique Fédérale de Lausanne (EPFL), CH-1015 Lausanne, Switzerland.
}

\author{
Abbreviations: \\ GABA: Gamma-Aminobutyric acid
}




\begin{abstract}
While various changes occur after spinal cord lesions, their influence on functional recovery is generally unclear. We have shown changes in proprioceptor and locomotor network properties below lesion sites in the lamprey spinal cord. The proprioceptive system offers a particularly tractable model for analyzing these changes. Here, we have sought evidence for changes in neuromodulatory effects below lesion sites by comparing the effects of GABA and somatostatin, both of which are located around the edge cells, on proprioceptive responses in lesioned and unlesioned spinal cords.
\end{abstract}

Exogenously applied GABA significantly reduced or abolished bending-evoked responses in unlesioned animals. In lesioned animals bending-evoked responses were stronger and certain of the effects of exogenously applied GABA were reduced. However, blocking endogenous GABA with bicuculline significantly potentiated responses in lesioned but not unlesioned animals. This suggested that the potentiated responses in lesioned animals were nevertheless associated with stronger tonic GABAergic inhibition. There were significant differences in these effects when lesioned animals were separated on the basis of their degree of recovery: notably, bicuculline only potentiated responses in animals that recovered good locomotor function, suggesting a need for raised endogenous GABA levels. Somatostatin alone did not affect edge cell responses in lesioned or unlesioned animals, but in lesioned animals it reduced and thus further weakened the inhibitory effects of GABA.

There are thus multiple changes in sensory modulation in the lesioned spinal cord, and differences in these effects may influence the degree of recovery. 
Keywords: lamprey spinal cord, functional recovery, mechanosensory neurons, neuromodulation, GABA, somatostatin.

\begin{abstract}
Various anatomical and functional changes occur after spinal cord lesions (Muir and Steeves, 1997; De Leon et al., 1998, 1999; Edgerton et al., 2001; Pearson, 2001; Rossignol et al., 2001; Wolpaw and Tennissen, 2001; Dietz et al., 2002; Fawcett, 2002; Li and Bennett, 2003; Harkema, 2008; Lavrov et al., 2008; Marsh et al., 2011; Rossignol and Frigon, 2011; Roy and Edgerton, 2012). Approaches to restoring function ultimately require insight into these changes, but in many cases their underlying mechanisms and influence on recovery is unknown.
\end{abstract}

Neuromodulation has been studied as a potential mechanism for promoting functional recovery after spinal cord injury (see Rossignol, 2001; Parker, 2005). Neuromodulation offers the potential of evoking diverse but integrated changes in system components (e.g. HarrisWarrick et al., 1998). However, while neuromodulators have a range of effects in lesioned animals, the analysis of these effects is complicated by variability that can be introduced by the type of injury, time after lesioning, cell specific effects of neuromodulators, and potential state-dependent effects caused by interactions between modulators. Developing rational pharmacological strategies to restore locomotor function after injury requires an understanding of modulatory systems in the intact spinal cord (to identify candidate target systems) and also in the lesioned spinal cord (to identify any changes that will alter their effects).

The larval lamprey is a model system for examining regeneration and functional recovery after spinal cord lesions (Rovainen, 1979; Cohen et al., 1988; McClellan, 1994). The larval transformation to the adult state begins after several years, and thus larvae offer a 


\section{Experimental Procedures}

Larval lampreys (Pertomyzon marinus) between 100-130 mm were obtained from commercial suppliers (Acme Lamprey Company, Maine, USA). To perform spinal cord transections, animals were anaesthetized by immersion in MS-222 $(300 \mathrm{mg} / \mathrm{ml}, \mathrm{pH}$ adjusted 
to 7.4 ), and a $\sim 5 \mathrm{~mm}$ dorsal incision was made approximately $1 \mathrm{~cm}$ below the last gill to expose the spinal cord. The spinal cord was then transected completely with iridectomy scissors. Following transection, animals were kept at $23^{\circ} \mathrm{C}$ for $8-10$ weeks (unlesioned animals were also kept at this temperature). At this time most animals have recovered locomotor function (McClellan, 1994), and the injury at the lesion site had healed completely.

Locomotor function in unlesioned and lesioned animals was assessed from video and electromyogram recordings and scored according to a six-point scale (see Cooke and Parker, 2009; Hoffman and Parker, 2011). EMG recordings were made by inserting bipolar teflon insulated electrodes $(0.075 \mathrm{~mm}$ in diameter) into the muscle under MS-222 anesthesia. Electrodes were inserted approximately $0.5 \mathrm{~cm}$ rostral and caudal to the lesion site. After recovery from anesthesia muscle activity was recorded as the animals swam in a plastic aquarium $(29 \times 23.5 \times 5.5 \mathrm{~cm})$. Swimming activity was initiated by lightly pinching the tail or head of the animal using serrated forceps. Swimming performance was scored independently by two experimenters. For the extremes of swimming performance used in this analysis (i.e. stage $1 / 2$ and 5/6) there was total agreement on the rating.

To examine movement-related feedback in the isolated spinal cord, lesioned and unlesioned animals were anaesthetized with MS-222 and the spinal cord and notochord from the trunk region (i.e. between the last gill and the start of the dorsal fin) were removed in oxygenated lamprey Ringer at $4^{\circ} \mathrm{C}$ (Ringer contents: $138 \mathrm{mM} \mathrm{NaCl}, 2.1 \mathrm{mM} \mathrm{KCl} ; 1.8 \mathrm{mM}$ $\mathrm{CaCl}_{2} ; 2.6 \mathrm{mM} \mathrm{MgCl}$; $4.0 \mathrm{mM}$ D-(+)-glucose; $2.0 \mathrm{mM}$ HEPES; 0.5 mM L-glutamine, bubbled with $\mathrm{O}_{2}$ and adjusted to $\mathrm{pH} 7.4$ with $1 \mathrm{M} \mathrm{NaOH}$ ). The isolated spinal cord and notochord was pinned to a Sylgard lined chamber and bathed in lamprey Ringer at $9^{\circ} \mathrm{C}$ in all experiments. This is a different temperature to that at which the animals were maintained. This was due to competing temperature requirements: recovery is optimal at warmer 
temperatures (Cohen et al., 1999), whereas the isolated spinal cord survives better at lower temperatures (experiments are routinely performed at the temperature we used). As the lamprey is cold-blooded and lives in streams at temperatures from just above freezing to approximately $20^{\circ} \mathrm{C}$, the differences in temperature should not introduce any significant issues. The spinal cord was fixed so that only approximately $1.5 \mathrm{~cm}$ of the rostral end could move (Fig. 1). The bending point was thus approximately $0.5 \mathrm{~cm}$ below the lesion site. A syringe tip (25-gauge) was attached to a vertical arm connected to a custom made motor that moved the vertical arm sinusoidally $1 \mathrm{~cm}$ to the left and right of center (this displacement was comparable to previously used bending parameters; Kiemel and Cohen, 2001; Tytell and Cohen, 2008; McClellan and Sigvardt, 1988; Hoffman and Parker, 2011). We have only used $1 \mathrm{~Hz}$ stimulation here as a previous study showed that $0.1-1 \mathrm{~Hz}$ stimulation revealed little frequency-dependent effect on bending responses in control and lesioned animals (Hoffman and Parker, 2011). $1 \mathrm{~Hz}$ stimulation also provided a physiologically-relevant stimulus within the range used previously (Kiemel and Cohen, 2001; Tytell and Cohen, 2008; McClellan and Sigvardt, 1988), and it allowed us to assess changes over repetitive trials in control and in the presence of modulators, while reducing the risk of introducing accumulative long-term changes that could occur if multiple stimulation frequencies were examined (Kiemel and Cohen, 2001). The syringe tip was bent to create a hook that was inserted through the ventral side of the notochord approximately $2 \mathrm{~mm}$ from the rostral end (i.e. the end free to move). Imposed sinusoidal movements of the isolated spinal cord/notochord that mimicked bending during swimming were programmed in MatLab. Bending trials lasted for $60 \mathrm{~s}$, and consisted of the initial $20 \mathrm{~s}$ of no bending, $20 \mathrm{~s}$ of bending, and the final $20 \mathrm{~s}$ of no bending. These trails were repeated every $2 \mathrm{~min}$, to give three trials in control, drug, or wash. We saw no cumulative change in bending responses over the repetitive trials. 
Extracellular recordings were made from the surface of the lateral tract using glass suction electrodes to monitor movement-related sensory feedback (see Grillner et al., 1982; McClellan and Sigvardt, 1988). Movement-related responses in this region reflect the activity of edge cells, intraspinal mechanoreceptors with cell bodies on the lateral edge of the spinal cord (Rovainen, 1979). The lateral tract also contains the axons of descending brainstem neurons (Rovainen, 1979). While we cannot unequivocally identify edge cells from extracellular recordings, as the imposed movements were behaviorally relevant $(1 \mathrm{~cm}$ deflections at $1 \mathrm{~Hz}$ ) it would seem unlikely that non-proprioceptive axons running in the lateral tracts would have been activated as they would then also be activated by normal swimming movements. As the edge cells are stretch-sensitive the activation of edge cells with contralateral or ipsilateral projecting axons (Vianan di Prisco et al., 1990) can be determined from the response to stretch (ipsilateral axon) or compression (contralateral axon) relative to the side that the recording is made from. Recordings were made approximately 7 segments caudal to the bending point (we have seen no difference in effects at 3, 7, and 12 segments caudal to the bending point; Hoffman and Parker, 2011). The edge cells also have ascending axons (see Tang and Selzer, 1979). We have only examined descending effects here to match our previous analysis (Hoffman and Parker, 2011), but rostral or caudal bending that activates descending or ascending axons, respectively, show similar effects (McClellan and Sigvardt, 1988), although there is some controversy over whether there is a difference in the entrainment of locomotor activity at the rostral and caudal ends (McClellan and Sigvardt, 1988, Tytell and Cohen, 2008). In all recordings, the peak of the wavelength represented compression (i.e. bending of the spinal cord to the same side as the recording electrode), while the trough corresponded to stretch (i.e. bending to the contralateral side; see Fig. 1).

Activity evoked during bending was quantified by detecting spikes offline using pClamp9 software (Clampfit 9.0, Axon Instruments Inc.). The time of each spike was logged 


\section{Results}

GABA reduces bending responses in both lesion and unlesioned spinal cords

In unlesioned animals responses to bending showed adaptation over repeated cycles (ratio of $10^{\text {th }}$ response to the $1^{\text {st }}$ was $0.4 \pm 0.08$ for contralateral bending and $0.79 \pm 0.33$ for 
ipsilateral bending; only contralateral adaptation was significant; Wilcoxon matched pairs test, $p<0.05, \mathrm{n}=9$; Fig. 3A). The peak phase activity (PPA) in unlesioned animals varied between experiments ( $418 \pm 116 \mathrm{~ms}$; Fig. 3Bi), which could reflect the recording of cells with different response patterns in different experiments. The fraction of spikes within 150 ms of the peak phase activity (fPPA) was $0.56 \pm 0.13$ (Fig. 3Bii), which suggested some degree of phase locking around the peak activity in individual experiments. GABA ( $1 \mathrm{mM}$; Christenson et al., 1991) significantly reduced the response to ipsilateral and contralateral bending on both the first and tenth responses ( $\mathrm{n}=9, p<0.05$, Kruskal-Wallis; Fig. 2, 3A), an effect consistent with the inhibitory effect of GABA on the edge cells (Christenson et al., 1991). In GABA, the bending-evoked responses were abolished in 6 of the 9 experiments and thus its effects on adaptation, PPA, and fPPA could not be examined statistically due to the low sample size (see Fig. 3Bi, Bii for a summary of the effects where activity was evoked). The effects of GABA had recovered on wash-off for 30 min-1 h.

In lesioned animals ipsilateral and contralateral bending-evoked responses were significantly potentiated compared to unlesioned animals $(\mathrm{n}=46 ; p<0.05$, Kruskal-Wallis; compare Fig. 3A, C; see also Hoffman and Parker, 2011) and adaptation was not significant for either ipsilateral or contralateral bending (Fig. 3C). As in unlesioned animals, the $1^{\text {st }}$ and $10^{\text {th }}$ contralateral bending-evoked responses were significantly reduced in $1 \mathrm{mM}$ GABA $(\mathrm{n}=$ 24, $p<0.05$, Kruskal-Wallis; Fig. 3C), and recovered on wash-off for $30 \mathrm{~min}-1 \mathrm{~h}$. The magnitude of the reduction of the contralateral bending-evoked responses by GABA did not differ significantly in lesioned or unlesioned animals ( $p>0.05$, Kruskal-Wallis). However, in contrast to contralateral bending-evoked effects, responses to ipsilateral bending were not significantly reduced by GABA in lesioned animals $(\mathrm{n}=24, p>0.05$, Kruskal-Wallis; Fig. 3C), suggesting a reduced GABAergic inhibitory effect. There was no significant effect of GABA on the rate of adaptation for either ipsilateral or contralateral bending (data not 
shown). The PPA was significantly reduced by GABA (from $459 \pm 76 \mathrm{~ms}$ to $230 \pm 84 \mathrm{~ms}, p$ $<0.05$, Wilcoxon matched pairs test; Fig. 3Di), but the fPPA was not significantly affected $(0.5 \pm 0.08$ compared to $0.49 \pm 0.09$ in GABA, $p>0.05$, Wilcoxon matched pairs test; Fig. 3Dii).

The $G A B A_{A}$ receptor antagonist bicuculline potentiates bending responses in lesioned spinal cords

The larger bending-evoked responses in lesioned animals could reflect reduced endogenous GABAergic inhibition. This was examined using the $\mathrm{GABA}_{\mathrm{A}}$ receptor antagonist bicuculline (10 $\mu \mathrm{M}$; Tegnér et al., 1993). In unlesioned animals bicuculline had no significant effect on bending responses ( $p>0.05$, Kruskal-Wallis, $n=5$; Fig. 4A,Ci), suggesting against the antagonism of a significant basal GABAergic inhibition of the edge cells (bicuculline also failed to affect the centrally-generated phasic modulation of the edge cells in unlesioned adult animals; see Vinay et al., 1996). However, in lesioned animals bicuculline increased the ipsilateral and contralateral bending-evoked responses, with significant effects occurring at the $10^{\text {th }}$ response $(p<0.05, \mathrm{n}=14$, Kruskal-Wallis; Fig. 4B). This increase over repeated bending cycles resulted in facilitation of the response rather than the adaptation seen in control (Fig. 4B, Cii). Bicuculline did not affect the PPA or fPPA in unlesioned animals (data not shown). In lesioned animals it significantly reduced the PPA (from $486 \pm 77 \mathrm{~ms}$ to $168 \pm$ $69 \mathrm{~ms}, \mathrm{n}=6, p<0.05$, Wilcoxon matched pairs test; Fig. 4Di) but did not significantly affect the fPPA (from $0.35 \pm 0.02$ to $0.39 \pm 0.03, \mathrm{n}=6, p>0.05$, Wilcoxon matched pairs test; Fig. 4Dii).

These results suggested that despite the potentiated responses to bending in lesioned animals, the edge cells were subject to greater endogenous tonic GABAergic inhibition. This 


\section{GABAergic effects are influenced by the degree of recovery}

These results suggest that there are changes in the GABAergic regulation of proprioceptive activity in lesioned animals. Animals can show varying degrees of recovery and most animals normally recover good locomotor function (assessed as stage 5 or 6 on a six-point functional scale; Cooke and Parker, 2009), but some animals can also show various dysfunctions (stage 1 or 2; see Hoffman and Parker, 2011). To examine whether the degree of recovery was associated with differences in edge cell modulation we examined the effects of 
GABA in animals that recovered good (stage 5/6) or poor locomotor function (stage 1/2; Cooke and Parker, 2009).

The contralateral and ipsilateral bending responses in stage $1 / 2$ animals $(n=16)$ and stage 5/6 animals $(n=12)$ did not differ statistically ( $p>0.05$, Kruskal-Wallis; Fig. 5A), suggesting that the potentiation of sensory responses does not simply correlate with the degree of recovery (see Hoffman and Parker, 2011). However, responses in both stage 1/2 and stage 5/6 animals were significantly greater than those in unlesioned animals $(p<0.05$, Kruskal-Wallis; see Fig. 3A, Fig. 5A). In response to GABA, there was a significant reduction of the $1^{\text {st }}$ contralateral bending response in stage $1 / 2(n=8)$ and stage $5 / 6$ animals ( $\mathrm{n}=11, p<0.05$, Kruskal-Wallis; Fig. $5 \mathrm{~B}, \mathrm{C})$, but while reduced the $1^{\text {st }}$ or $10^{\text {th }}$ ipsilateral effects were again not significantly affected ( $p>0.05$, Kruskal-Wallis; data not shown). However, while the $10^{\text {th }}$ contralateral response was significantly reduced by GABA in stage 5/6 animals it was not significantly affected in stage 1/2 animals (compare Fig. 5B, C), suggesting reduced GABAergic effects in poorly recovered animals. In addition, significant effects of bicuculline were also only seen in animals that recovered to stage $5 / 6(n=8)$, not in those that recovered poorly $(\mathrm{n}=6 ; p<0.05$, Kruskal-Wallis; Fig. 5D, E), which suggested that tonic GABA levels were only increased in the animals that recovered well.

\section{Somatostatin inhibits GABA effects in lesioned spinal cords}

The lateral edge of the spinal cord receives both somatostatin and GABAergic inputs (Christenson et al., 1991). GABA and, less reliably, somatostatin can hyperpolarize the edge cells (Christenson et al., 1991). The effects of somatostatin and GABA were thus also examined sequentially here. In unlesioned animals GABA $(1 \mathrm{mM})$ again significantly reduced or abolished ipsilateral and contralateral bending-evoked activity $(p<0.05$, Kruskal 


\section{Discussion}

This study has examined the modulation of proprioceptive responses after spinal cord lesions in the lamprey. The results suggest that there are differences in neuromodulation in lesioned animals, and that some of these effects were associated with the degree of functional recovery.

The edge cells underlying proprioceptive responses have excitatory ipsilateral or contralateral inhibitory projections (see Fig. 7). As the edge cells are stretch-sensitive, 
ipsilateral bending (i.e. bending toward the same side as the recording electrode) will compress rather than stretch edge cells on that side (see Fig. 1). The evoked response to this bending is thus assumed to reflect the activity of edge cells with crossing inhibitory axons activated by stretch on the opposite side of the body (Viana Di Prisco et al., 1990). Responses to contralateral bending will reflect the activation of excitatory edge cells ipsilateral to the recording electrode (see Viana Di Prisco et al., 1990; see Fig. 7). GABA markedly reduced all proprioceptive responses in unlesioned animals, but it had reduced effects in lesioned animals as it did not significantly reduce ipsilateral bending-evoked responses. Conversely, blocking endogenous $\mathrm{GABA}_{\mathrm{A}}$ with bicuculline had significantly stronger effects in lesioned animals suggesting greater endogenous GABA effects. Somatostatin had no direct effect in lesioned or unlesioned animals, but in lesioned animals it blocked the effects of GABA, suggesting the potential for regulation of GABA inhibition by the release of co-localized somatostatin (Christenson et al., 1991).

The reduced inhibitory effects of GABA in lesioned animals could reflect several mechanisms. The effects of inhibitory transmitters coupled to chloride channels can change as the chloride equilibrium potential is depolarized due to changes in potassium-chloride cotransport (Boulenguez et al., 2010). However, if this effect was occurring here bicuculline should have reduced and GABA should have increased excitability, opposite effects to those seen here. Higher endogenous GABA levels after lesioning could have reduced the effects of exogenously applied GABA, although there would need to be specific regional differences in GABA levels to account for the differences in ipsilateral and contralateral bending-evoked responses. There may be some difference in the effects of $\mathrm{GABA}_{\mathrm{A}}$ and $\mathrm{GABA}_{\mathrm{B}}$-mediated responses, but these remains to be determined. Finally, the reduced effects of GABA on ipsilateral bending responses in lesioned animals could reflect a change in the properties or numbers of GABA receptors on contralaterally projecting cells. Whatever the mechanism, the 
differences in ipsilateral and contralateral bending-evoked responses suggest some functional re-organization of the proprioceptive system after lesioning.

In any integrated system changes in one property must be balanced by changes in other properties. Disturbances in the interaction between spinal cord locomotor networks and their inputs could lead to various motor dysfunctions (see Bennett, 2008). Potentiated proprioceptive responses may reflect the increase in edge cell excitability (see Hoffman and Parker, 2011). The stronger endogenous GABA inhibition suggested by the effects of bicuculline may reflect a necessary compensation in response to this effect that regulates the potentiated sensory inputs. The responses when endogenous GABA effects were blocked by bicuculline could be very strong and lead to facilitating high frequency bursts of edge cell activity, suggesting that the lesion-induced changes in the edge cells lead to the potential for runaway proprioceptive excitation in lesioned (but not unlesioned) animals when GABAmediated inhibition is compromised. While a causal link has not been determined, the reduced effects of bicuculline in animals that recovered poorly suggest that an increase in sensory input (which occurred in animals that recovered well or poorly) may contribute to poor recovery if it is not associated with increased endogenous GABA inhibition.

The lack of effect of somatostatin was surprising, as it is reported to hyperpolarize edge cells (Christenson et al., 1991). However, somatostatin inhibition was less reliable than that of GABA, and unlike GABA its effects were revealed when the edge cells were activated by the cord being stretched (see Christenson et al., 1991). These features all suggest a more subtle and potential state-dependent role for somatostatin than for GABA. In our experiments somatostatin alone had no significant effect on edge cell responses in lesioned or unlesioned animals. However, in lesioned animals somatostatin occluded the effects of exogenously applied GABA. This suggests that rather than a direct effect on the edge cells, somatostatin 
may instead modulate GABAergic inhibition. This will result in disinhibition, and thus promote stronger proprioceptive inputs.

\section{Functional effects}

While spinal cord excitability and sensory responses are potentiated below lesion sites (Cooke and Parker, 2009; Hoffman and Parker, 2011), we ultimately need to know how these effects influence recovery. In this respect we have so far been unsuccessful in that we have been able to make few correlations between the functional changes and the degree of recovery (Cooke and Parker, 2009; Hoffman and Parker, 2011). The lack of correlation may reflect the marked variability of functional effects which may need larger sample sizes or alternative analyses (see West, 2010; Aradi and Soltesz, 2002). We also have to consider that the qualitative scoring of recovery is relatively subjective. The extremes of the scale that we have used (stage $1 / 2$ and 5/6) can be unequivocally defined, but there are almost certainly going to be differences in mechanisms between and within these stages. The scoring scale that we have used thus only allows us to relate the effects studied to differences in behavioral performance. Relating effects to their underlying mechanisms will only be possible with greater insight into the changes that occur below lesion sites (Cooke and Parker, 2009; Hoffman and Parker, 2011).

Our results show that even when performing a simple analysis in what is considered to be a relatively simple system there are complex and wide-ranging changes. In unlesioned animals GABA essentially abolished all edge cell responses. In lesioned animals it only significantly reduced responses to contralateral bending. Why should responses to ipsilateral bending be less affected by GABA in lesioned animals? As outlined above, the edge cells are stretch-sensitive and have axons that project ipsilaterally and contralaterally (Rovainen, 1974). Bending ipsilateral to the recording site (i.e. compression; see Fig. 7) will reflect the 


\section{References}

Aradi I, Soltesz I (2002), Modulation of network behaviour by changes in variance in interneuronal properties. J Physiol (Lond) 538:227-251.

Bennett DJ (2008), Demystifying spasticity. J Neurophsyiol 99:1041-1043.

Boulenguez P, Liabeuf S, Bos R, Bras H, Jean-Xavier C, Brocard C, Stil A, Darbon P, Cattaert D, Delpire E, Marsala M, Vinay L (2010), Down-regulation of the potassiumchloride cotransporter KCC2 contributes to spasticity after spinal cord injury. Nat Med $16: 302-307$.

Christenson J, Alford S, Grillner S, Hökfelt T (1991), Co-localized GABA and somatostatin use different ionic mechanisms to hyperpolarize target neurons in the lamprey spinal cord. Neurosci Lett 134:93-97.

Cohen AH, Mackler SA, Selzer ME (1988), Behavioral recovery following spinal transection: functional regeneration in the lamprey CNS. Trends in Neurosci 11:227-231.

Cooke RM, Parker D (2009), Locomotor recovery after spinal cord lesions in the lamprey is associated with functional and ultrastructural changes below lesion sites. J Neurotrauma 26:597-612.

Debarbieux F, Brunton J, Charpak S (1998), Effect of bicuculline on thalamic activity: a direct blockade of $I_{A H P}$ in reticularis neurons. J Neurophysiol 79:2911-2918.

De Leon RD, Hodgson JA, Roy RR, Edgerton VR (1998), Locomotor capacity attributable to step training versus spontaneous recovery after spinalization in adult cats. J Neurophysiol 79:1329-1340. 
De Leon RD, Hodgson JA, Roy RR, Edgerton VR (1999), Retention of hindlimb stepping ability in adult spinal cats after the cessation of step training. J Neurophysiol 81:85-94.

Dietz V, Müller R, Colombo G (2002), Locomotor activity in spinal man: significance of afferent input from joint and load receptors. Brain 125:2626-2634.

Edgerton VR, Leon RD, Harkema SJ, Hodgson JA, London N, Reinkensmeyer DJ, Roy RR, Talmadge RJ, Tillakaratne NJ, Timoszyk W, Tobin A (2001), Retraining the injured spinal cord. J Physiol 533:15-22.

Edgerton VR, Courtine G, Gerasimenko YP, Lavrov I, Ichiyama RM, Fong AJ, Cai LL, Otoshi CK, Tillakaratne NJ, Burdick JW, Roy RR (2008), Training locomotor networks. Brain Res Rev 57:241-254.

Fawcett J (2002), Repair of spinal cord injuries: where are we, where are we going? Spinal Cord 40:615-623.

Grillner S, McClellan A, Sigvardt K (1982), Mechanosensitive neurons in the spinal cord of the lamprey. Brain Res 235:169-173.

Grillner S, Williams T, Lagerbäck P-A (1984), The edge cell, a possible intraspinal mechanoreceptor. Science 223:500-503.

Harkema SJ (2008), Plasticity of interneuronal networks of the functionally isolated human spinal cord. Brain Res Rev 57:255-264.

Harris-Warrick RM, Johnson BR, Peck JH, Kloppenburg P, Ayali A, Skarbinski J (1998), Distributed effects of dopamine modulation in the crustacean pyloric network. Ann NY Acad Sci 860:155-167. 
Hill R, Matsushima T, Schotland J, Grillner S (1992), Apamin blocks the slow AHP in lamprey and delays termination of locomotor bursts. Neuroreport 3:943-945.

Hoffman N, Parker D (2011), Interactive and individual effects of sensory potentiation and region-specific changes in excitability after spinal cord injury. Neuroscience 199:563-576.

Kiemel T, Cohen A (2001), Bending the lamprey spinal cord causes a slowly-decaying increase in the frequency of fictive swimming. Brain Res 900:57-64.

Lavrov I, Dy C, Fong AJ, Gerasimenko Y, Courtine G, Zhong H, Roy RR, Edgerton VR (2008), Epidural stimulation induced modulation of spinal locomotor networks in adult spinal rats. J Neurosci 28:6022-6029.

Li Y, Bennett DJ (2003), Persistent sodium and calcium currents cause plateau potentials in motoneurons of chronic spinal rats. J Neurophysiol 90:857-869.

Marsh BC, Astill SL, Utley A, Ichiyama RM (2011), Movement rehabilitation after spinal cord injuries: emerging concepts and future directions. Brain Res Bull 84:327-336.

McClellan AD (1994), Functional regeneration and restoration of locomotor activity following spinal cord transection in the lamprey. Prog Brain Res 1994 103:213-217.

McClellan AD, Sigvardt KA (1988), Features of entrainment of spinal pattern generators for locomotor activity in the lamprey spinal cord. J Neurosci 8:133-145.

Muir GD, Steeves JD (1997), Sensorimotor stimulation to improve locomotor recovery after spinal cord injury. Trends in Neurosci 20:72-77.

Parker D (2003), Variable properties in a single class of excitatory spinal synapse. J Neurosci 23:3154-3163. 
Parker D (2005), Pharmacological approaches to functional recovery after spinal injury. Curr Drug Targets CNS Neurol Disord 4:195-210.

Parker D, Bevan S (2007), Modulation of cellular and synaptic variability in the lamprey spinal cord. J Neurophysiol 97:44-56.

Pearson KG (2001), Could enhanced reflex function contribute to improving locomotion after spinal cord repair? J Physiol (Lond) 533:75-81.

Rossignol S, Frigon A (2011), Recovery of locomotion after spinal cord injury: some facts and mechanisms. Ann Rev Neurosci 34:413-440.

Rossignol S, Giroux N, Chau C, Marcoux J, Brustein E, Reader TA (2001), Pharmacological aids to locomotor training after spinal injury in the cat. J Physiol 533:65-74.

Rovainen CM (1974), Synaptic interactions of identified nerve cells in the spinal cord of the sea lamprey. J Comp Neurol 154:189-206.

Rovainen CM (1979), Neurobiology of lampreys. Physiol Rev 59:1007-1077.

Roy RR, Edgerton VR (2012), Neurobiological perspective of spasticity as it occurs after spinal cord injury. Exp Neurol 235:116-122.

Tang D, Selzer ME (1979), Projections of lamprey spinal neurons determined by the retrograde axonal transport of horseradish peroxidase. J Comp Neurol 188:629-645.

Tegnér J, Matsushima T, El Manira A, Grillner S (1993), The spinal GABA system modulates burst frequency and intersegmental coordination in the lamprey: differential effects of $\mathrm{GABA}_{\mathrm{A}}$ and $\mathrm{GABA}_{\mathrm{B}}$ receptors. J Neurophysiol 69:647-657. 
Tytell ED, Cohen A (2008), Rostral versus caudal differences in mechanical entrainment of the lamprey central pattern generator for locomotion. J Neurophysiol 99:2408-2419.

Verhage M, McMahon HT, Ghijsen WE, Boomsma F, Scholten G, Wiegant VM, Nicholls DG (1991), Differential release of amino acids, neuropeptides, and catecholamines from isolated nerve terminals. Neuron 6:517-524.

Viana Di Prisco G, Wallén P, Grillner S (1990), Synaptic effects of intraspinal stretch receptor neurons mediating movement-related feedback during locomotion. Brain Res 530:161-166.

Vinay L, Barthe JY, Grillner S (1996), Central modulation of stretch receptor neurons during fictive locomotion in lamprey. J Neurophysiol 76:1224-1235.

West BJ (2010), Fractal physiology and the fractional calculus: a perspective. Front in Physiol 1:1-17.

Wolpaw JR, Tennissen AM (2001), Activity-dependent spinal cord plasticity in health and disease. Ann Rev Neurosci 24:807-843.

Figure 1: (A) Diagram of the experimental set-up. The isolated spinal cord is fixed to a Sylgard-lined chamber. The rostral region of the spinal cord (to left) is free to move and is attached to a motor driven in MatLab to generate sinusoidal movements of the spinal cord at $1 \mathrm{~Hz}$ (compression corresponds to bending ipsilateral to the recording site, stretching to bending to the contralateral side relative to the recording site).

Figure 2: Example of the Matlab bending analysis. (A) A $20 \mathrm{~s}$ bending frame in an unlesioned animal, and (B) after 10 min application of 1 mM GABA. (Ai, Bi) The time (x- 
Figure 3: The effects of GABA on bending-evoked responses in control and lesioned animals. (A) The effects of $1 \mathrm{mM} \mathrm{GABA}$ on the $1^{\text {st }}$ and $10^{\text {th }}$ responses to bending contralateral and ipsilateral to the recording electrode in an unlesioned animal. The asterix on this and other graphs represents significant effects at $p<0.05$. Graphs showing the peak phase activity (PPA; Bi) and fraction of activity around the peak phase (fPPA; Bii) in unlesioned animals in control and $1 \mathrm{mM}$ GABA. (C) The effects of $1 \mathrm{mM}$ GABA on bending responses in animals recorded 8-10 weeks after a complete spinal cord lesion. Note the difference in the y-axis scale in $3 \mathrm{~A}$ and $\mathrm{C}$. Note also that in lesioned animals GABA did not significantly affect ipsilateral bending responses. Graphs showing the PPA (Di) and PPPA (Dii) in lesioned animals in control and in GABA. (Ei) Traces showing the effects of GABA in an unlesioned animal. (Eii) Traces showing the effects of GABA in a lesioned animal.

Figure 4: Blocking endogenous GABA with bicuculline potentiates bending-evoked responses in lesioned animals. (A) Graph showing the effects of the $\mathrm{GABA}_{\mathrm{A}}$ receptor antagonist bicuculline $(10 \mu \mathrm{M})$ in spinal cords from unlesioned animals. (B) Graph showing the potentiating effects of bicuculline on bending-evoked responses in lesioned animals. 
Traces showing the effects of bicuculline in an unlesioned (Ci) and lesioned animal (Cii). Graphs showing the effects of bicuculline on the PPA (Di) and fPPA (Dii) in control and bicuculline. (E) The effects of bicuculline applied after application of the calcium-dependent potassium channel antagonist apamin $(2 \mu \mathrm{M})$. Note that bicuculline was still able to potentiate bending-evoked responses after apamin application.

Figure 5: The influence of the degree of recovery on the modulation of bending-evoked responses. (A) Graph showing bending response in animals that recovered poorly (defined as stage 1/2) or well (defined as stage 5/6 animals; see Experimental Procedures). The differences between these stages were not statistically significant. Graphs showing the effects of GABA $(1 \mathrm{mM})$ in animals that recovered poorly $(B)$ or well $(\mathrm{C})$. Note that the contralateral bending-evoked response was not significant in stage $1 / 2$ animals. Graphs showing the effects of bicuculline $(10 \mu \mathrm{M})$ in animals that recovered poorly (D) or well (E). Note also that bicuculline potentiation of the responses was absent in stage $1 / 2$ animals.

Figure 6: The interactive effects of GABA and somatostatin on bending-evoked responses. (A) Graph showing the effects of GABA $(1 \mathrm{mM})$ and somatostatin $(1 \mu \mathrm{M})$ on bendingevoked responses in unlesioned animals. Note that GABA significantly reduced responses on its own, and in the presence of somatostatin, but that alone somatostatin had no significant effect. (B) The effects of GABA, somatostatin, and somatostatin and GABA in lesioned animals. Note that the effects of GABA were reduced in the presence of somatostatin as the effects of GABA on contralateral bending-evoked effects were no longer significant in the presence of somatostatin. (C) Traces showing the effects of GABA and somatostatin in a lesioned animal. 
Figure 7: Diagram showing the connectivity between the edge cells and the locomotor network. The large square boxes show half-center networks on the left and right side of the body. The active half-center causes contraction of that side (right) and stretches the contralateral side (left). The active networks send excitatory inputs (white circles) to ipsilateral edge cells, and inhibitory inputs (black circles) to contralateral edge cells. Edge cells on the inactive (stretched) side of the body send excitatory inputs ipsilaterally (i.e. to the inactive half-center) and inhibitory inputs contralaterally (to the active half-center). 
Figure
Click here to download high resolution image

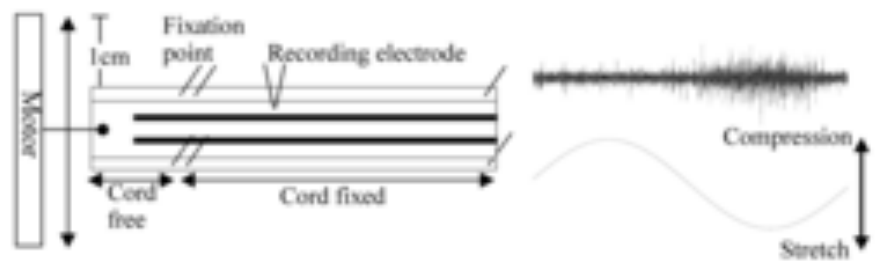


Figure
Click here to download high resolution image

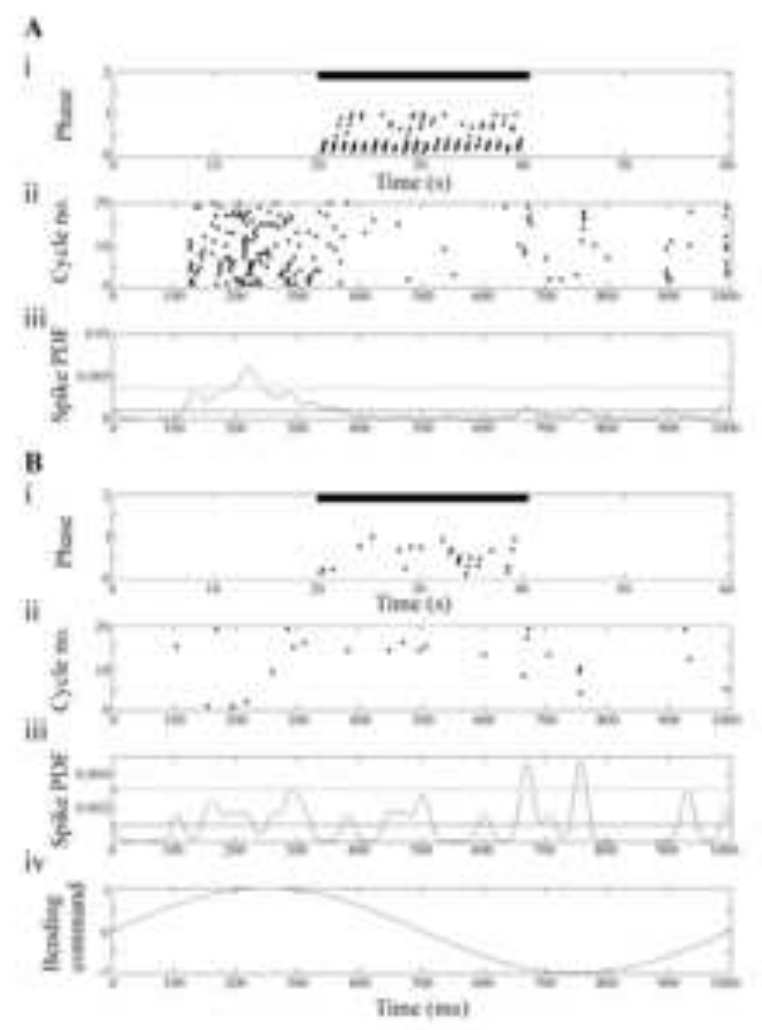




\section{Click here to download high resolution image}

A

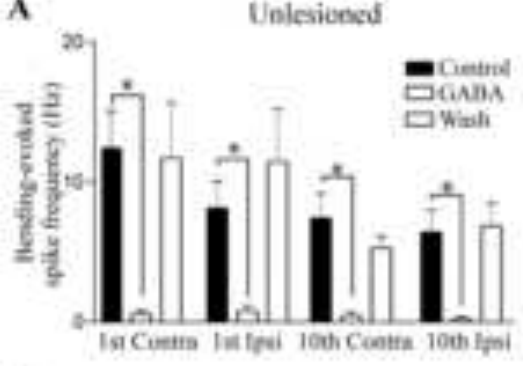

C
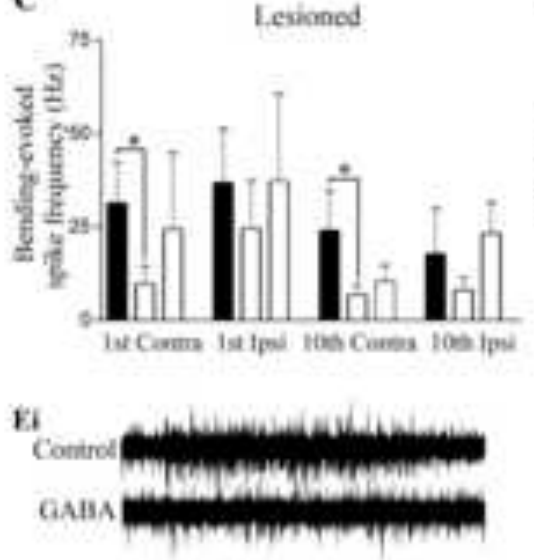

Ei

Eii

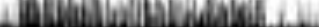

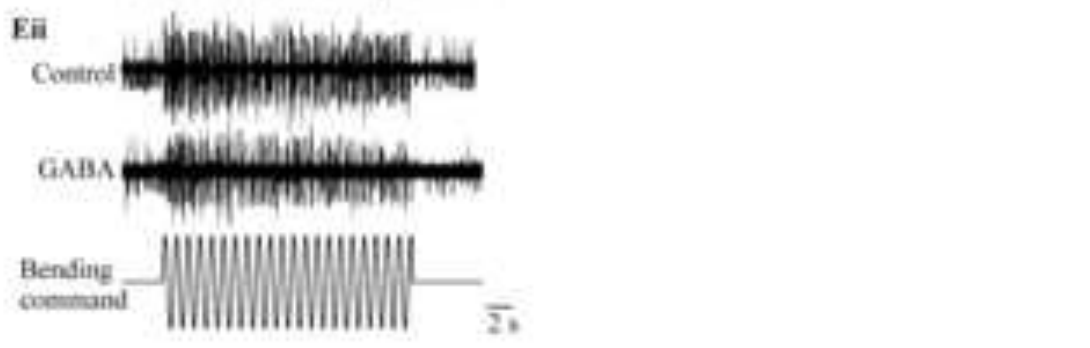

Bi

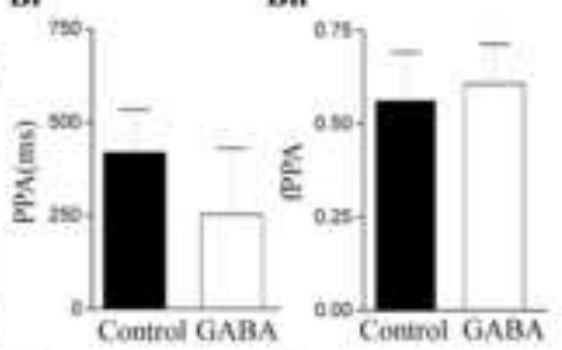

Di

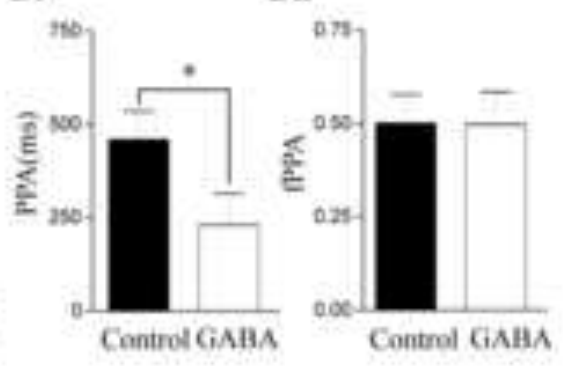

Dii

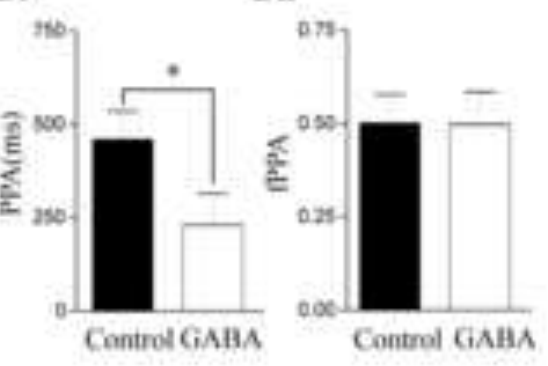

Bii
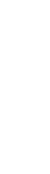
A

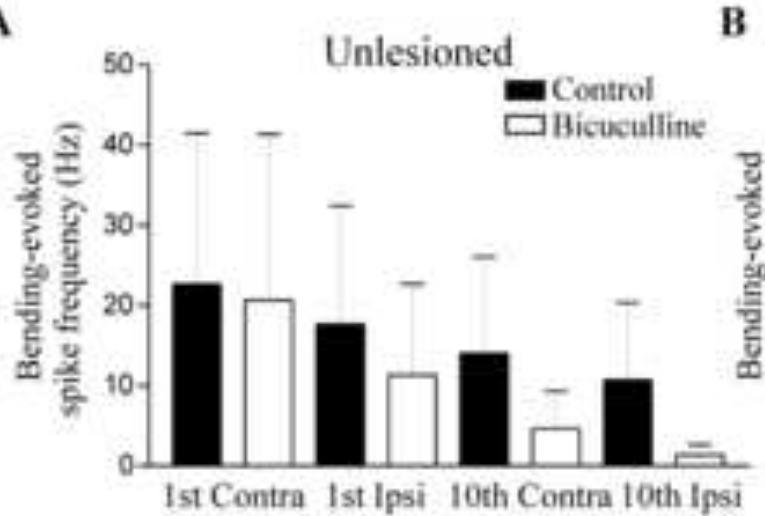

B
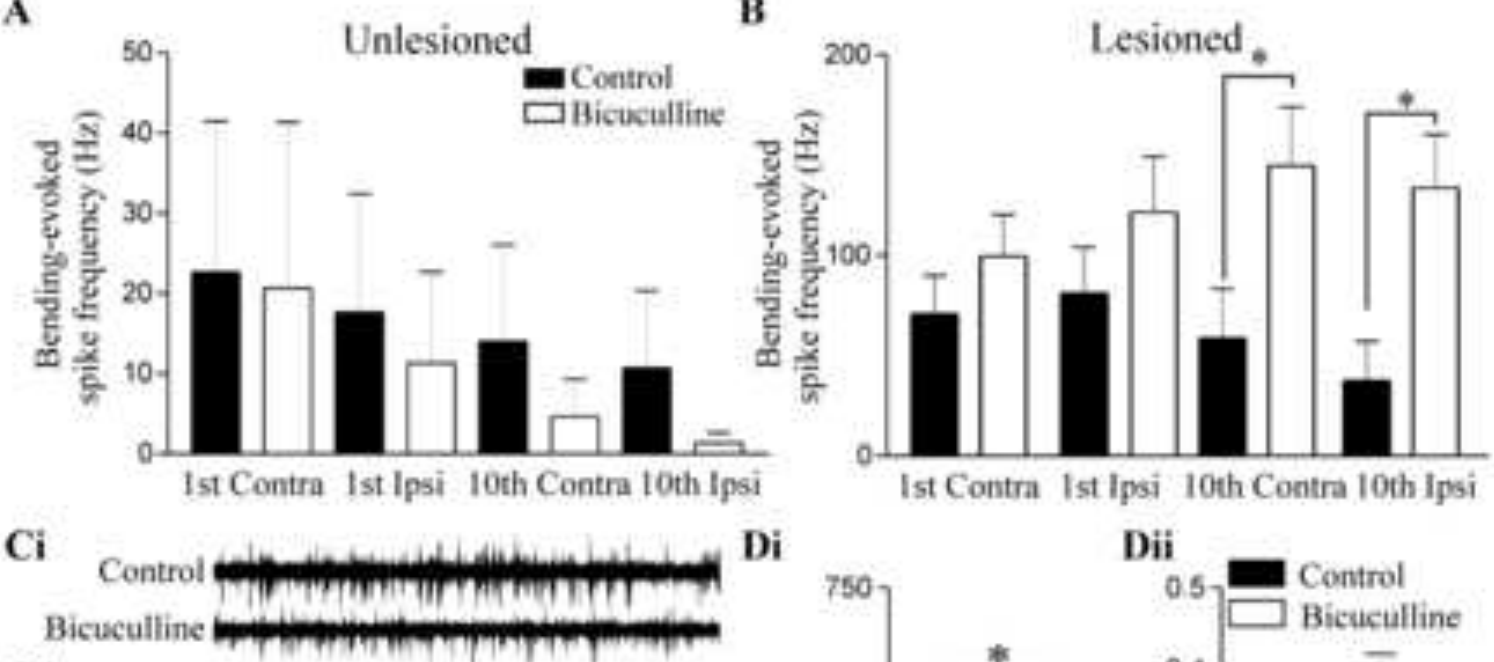

Di
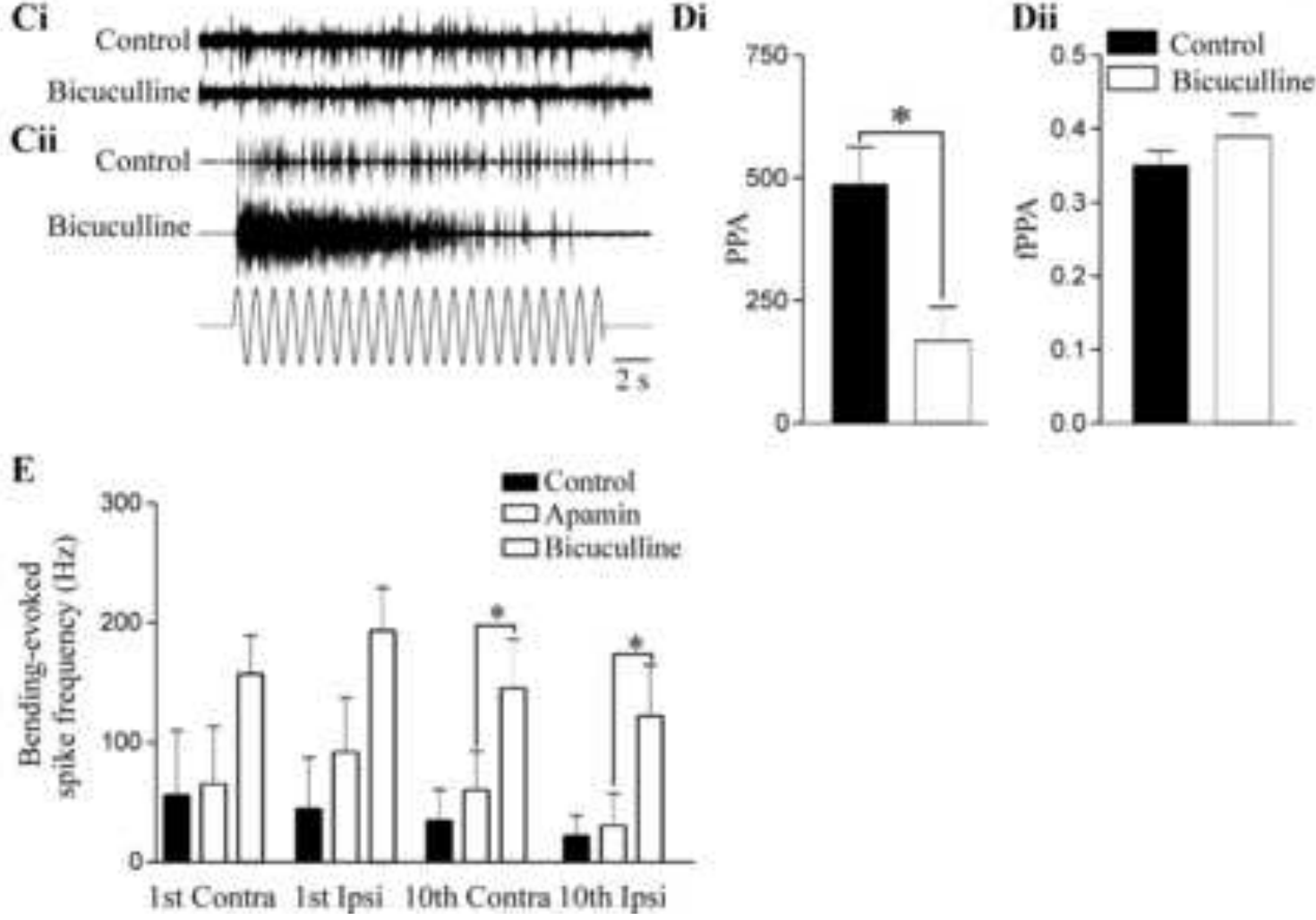


\section{Click here to download high resolution image}
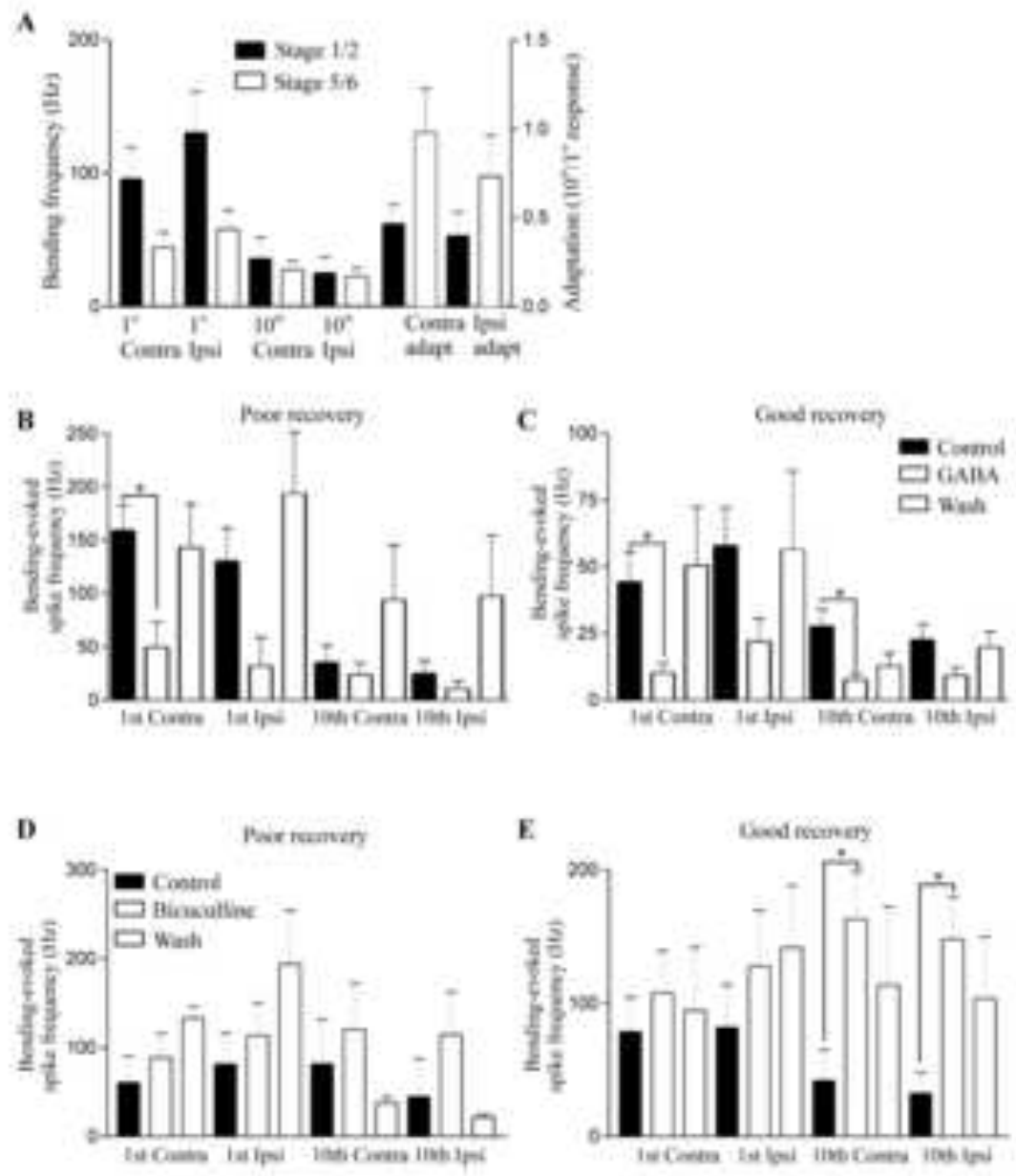

Figure 
Click here to download high resolution image

A

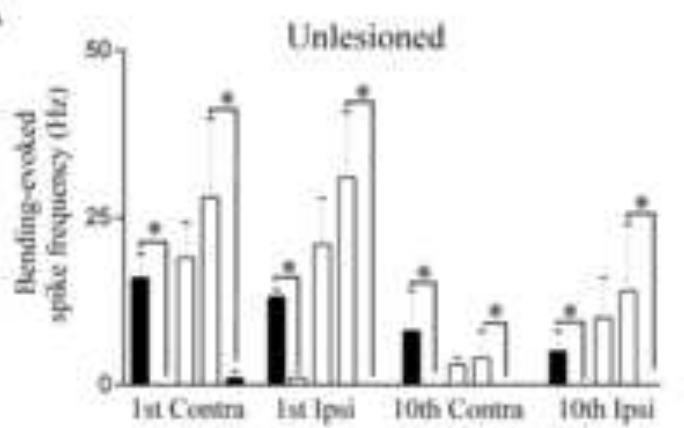

B

Lesioned $=$ Conitris

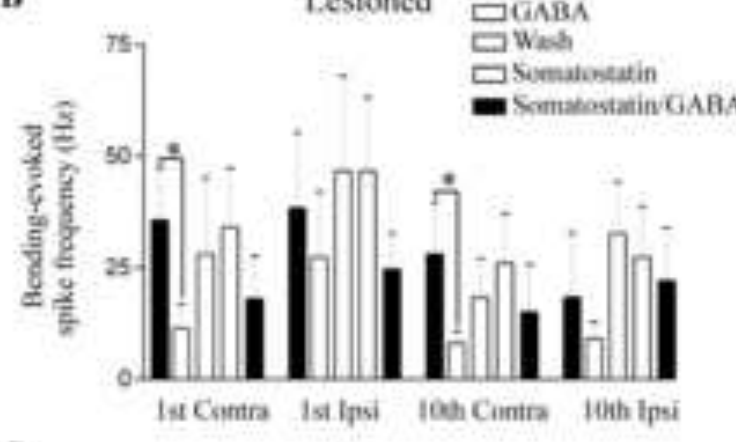

C
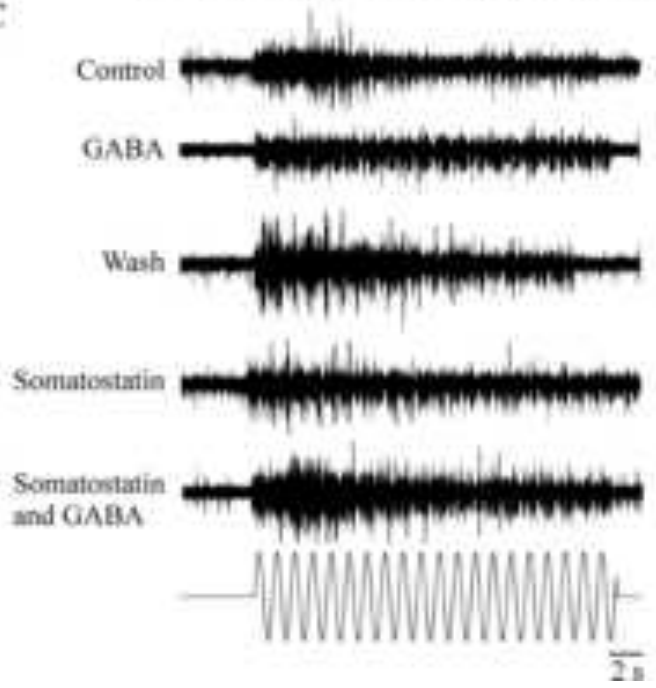
Figure
Click here to download high resolution image

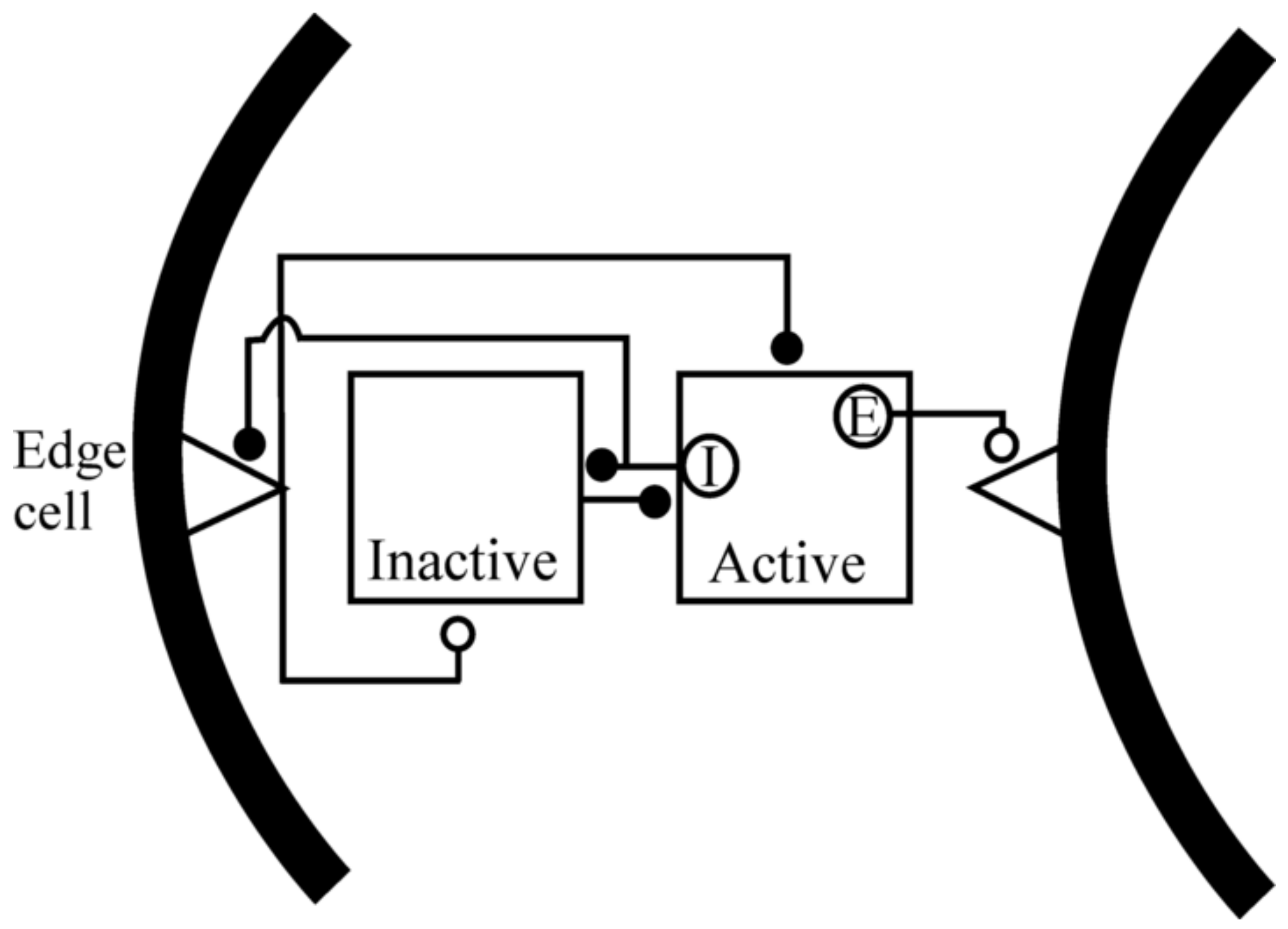

